Research Article

\title{
A Study on the Mechanisms of Tension-Shear Failure and the Estimation Model for Key Parameters of Free-Face-Assisted Rock Breaking
}

\author{
Chongmao Tang $\mathbb{D}^{1,2}$ \\ ${ }^{1}$ School of Mechanical and Electrical Engineering, Central South University, Changsha 410083, China \\ ${ }^{2}$ China Railway Construction Heavy Industry Corporation Limited, Changsha 410100, China \\ Correspondence should be addressed to Chongmao Tang; tangcm06csu@126.com
}

Received 9 June 2020; Revised 19 March 2021; Accepted 10 November 2021; Published 15 December 2021

Academic Editor: Timo Saksala

Copyright (c) 2021 Chongmao Tang. This is an open access article distributed under the Creative Commons Attribution License, which permits unrestricted use, distribution, and reproduction in any medium, provided the original work is properly cited.

One huge challenge TBM construction face is to improve the breaking ability of cutters for hard rocks, making the studies on new rock breaking approaches for cutters very important. Although a lot of previous tests have proved that it is feasible to reduce the cutter force by free-face-assisted rock breaking (FM), the mechanisms behind such feasibility and the estimation methods for key parameters involved, including the maximum free face distance, crushing angle, and cutting force, remain to be studied further, limiting its applications in cutterhead design and engineering construction practice. Based on the analysis of the phenomena and laws of FM tests, this paper proposes the tensile-shear failure mechanism of FM and a piecewise linear failure criterion, which could explain the reason for the reduction of cutting force. Subsequently, a series of estimation models for the parameters above are proposed, and a series of FM tests were performed. By comparing the data obtained from the tests and calculations of the estimation model and CSM model, the estimation model in this paper is verified for its feasibility and limitations, which offered some insights on these aspects in follow-up research.

\section{Introduction}

Disc cutters in TBM are highly efficient to break rocks, so they are currently the most widely applied mechanical construction equipment to build rock tunnels in the world. When breaking rocks, the disc ring of a disc cutter penetrates the rocks to a certain depth with a huge load. However, if the rock is extremely hard, it would be very difficult for the cutter to break the rock, and cutter loss grows rapidly, resulting in slow or even no progress in construction, thereby prolonging the tunnel construction period and increasing the construction cost $[1-5]$.

Regarding the problem mentioned above, new and better cutter materials and rock breaking methods can serve as a solution. However, it is still difficult to develop an economical and high-performance cutter material within the short term. As for the novel rock breaking methods, evidence shows that several previously proposed methods, such as high-pressure water jet-assisted rock breaking, microwaveassisted rock breaking, and disc cutter impact-vibration rock breaking, can sufficiently achieve the desired goal [6-8]. In the first two methods, the cutting force is significantly reduced, and rock breaking efficiency increases without extra force applied on the cutter. As for the last method, although the penetration depth and rock breaking efficiency are improved as well, the force the cutter endures also grows, making cutter failure more prone to occur.

Qi et al. proposed a two-stage cutterhead scheme and proved that their apparatus required less thrust than conventional flat cutterheads in given geological and penetration conditions $[9,10]$. Subsequently, Xuhui et al. [11, 12] conducted a series of tests and simulations on free-face- 
assisted rock cutting (FM) on a linear cutting machine (LCM) and found that FM could effectively reduce disc cutting force and achieve large volume rock fragmentation with a higher rock breaking efficiency than conventional rock cutting methods (CM).

In FM, the free surface is created by either a cutterhead with two or more stages [11] or a large depth slit carved by large flow water jets after its slow and repetitive cuts on the rocks (Figures 1(a) and 1(b)). However, the FM is still under preliminary research, and some key parameters still need deeper theoretical analysis and calculation. These parameters and their variation laws are important foundations to design cutter head structures, cutter layouts, free face layouts, and cutting parameters.

In this article, we propose a tension-shear failure mechanism and establish several estimation models for key parameters of FM, which could provide further insights for engineering applications.

\section{Analysis of the Phenomenon and Mechanism}

2.1. The Characteristics of FM. FM defined in this paper includes two equivalent ways of implementation (Figures 1(a) and 1(b)), where the crack propagation depth $L$ in Figure 1(b) satisfies $L<L_{m}$. At the FM state, the rock on the free face side is broken, exhibiting the following phenomena and characteristics $[11,12]$ :

(1) The distance between the cutter blade and the free face is defined as free face distance $S^{\prime}$, and a maximum free face distance $S_{\max }^{\prime}$ exists at a certain penetration value. Only when $S^{\prime} \leq S_{\max }^{\prime}$ can FM effects be produced.

(2) The angle between the fracture surface and the vertical direction is described as the rock crushing angle $\psi$. Despite different $S_{\max }^{\prime}$ numbers, $\psi$ and the shape of the failure surface remain close.

(3) Under the same penetration, the normal and rolling forces of FM are smaller than those of CM.

2.2. Analysis of the Rock Breaking Mechanisms of FM. There are three mainstream theories about the rock breaking mechanisms of disc cutter, namely shear fracture, tension fracture, and shear-tension fracture theories. The shear fracture theory holds that both compressive stress and shear stress will be produced on both sides of rock fractures when cutters penetrate rocks, and both stresses meet the Mohr-Coulomb criterion (M-C) [13]. The tensile fracture theory, derived from the Griffith crack propagation theory, believes that the process of rock breaking is essentially the formation, initiation, and propagation of tension cracks around the dense core under the cutter [14]. Finally, the shear-tension action theory considers rock breaking by disc cutter a process related to the synergistic effect of the shear failure and tensile failure mechanisms at different cutter spacings [15]. All three theories are valuable to analyze CM as well as FM.
From a microscopic perspective, tensile failure and shear failure are two major failure forms for rock micro-elements, and they usually coexist in rocks subject to external loads $[16,17]$. When compressive stress is the predominant form of stress, the main type of fracture is manifested by shear failure. As tensile stress on the fracture surface grows, tensile failure becomes more prominent. In addition, previous studies found that the comprehensive strength of rocks under tensile-shear stress will drop, making them easier to be destroyed. Huang and Zhu once performed tension-shear tests and PFC simulation on sandstone and revealed that the alteration of rock failure from shear failure to tension failure is a continuous process. Consequently, he proposed the concept of shear failure rate (SFR) to represent the proportion of shear and tension effect during rock failure [18].

From the rock breaking phenomenon and crack propagation rules of FM, the FM fracture surface is considered to be resembling a plane, and the surface morphology and geometric characteristics of the fracture surface are relatively regular and uniform, creating a large proportion of rock tensile failure $[12,13]$. Consequently, a tensile-shear failure hypothesis is proposed, which explains the failure mechanism of FM as the following. In rock failure, the cutter penetrates the rock and forms a powder layer or a dense core under the blade. Subsequently, the dense core transfers the normal force and part of the side force to the surrounding rocks instead of the blade, creating a tension-shear stress state in the side area of the rock free face. As the penetration depth of the cutter into the rock grows, initial microcracks begin to form on the boundary of the dense core. As the magnitudes and proportions of tensile and shear stresses on the fracture surface (area) vary in different directions (angles), the capability to propagate initial cracks is also different among the directions. Particularly, the combination of tensile stress and shear stress on a plane with a specific angle to the free face side is most likely to produce microcracks and their expansion to the free surface. When the cutter penetration depth (or the load required for crack propagation to the free face) satisfies the tension-shear failure demand of this plane, the fracture surface will take shape rapidly, eventually resulting in rock fracture.

Many engineering cases and laboratory tests show that compared to the compression-shear state (e.g. the CM state), the failure strength of rocks in the tension-shear state is significantly lower. Scholars have also studied the failure mechanisms and failure criteria of tension-shear. The widely used rock failure criteria include the linear $\mathrm{M}-\mathrm{C}$ and the non-linear $\mathrm{H}-\mathrm{B}$. The $\mathrm{M}-\mathrm{C}$ can produce good approximation results under compressive stress, but its estimation accuracy is much lower than the $\mathrm{H}-\mathrm{B}$ when simulating tensile stress [19-23].

Since M-C is easier in its forms and calculations, it is still widely used in many computer programs for engineering calculations and large-scale geotechnical analysis. Besides, the linearization method of $\mathrm{H}-\mathrm{B}$ has attracted much attention. Hoek proposed a parameter estimation method for equivalent $\mathrm{H}-\mathrm{B}$ under different conditions, and the estimation results were are close to the real situation in the compressive region of $\tau-\sigma$ space, but the estimation error 


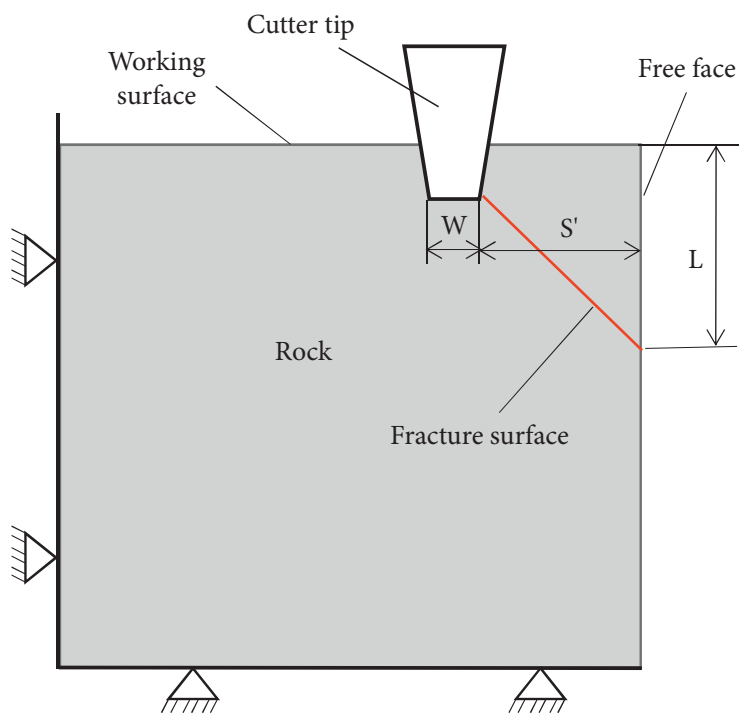

(a)

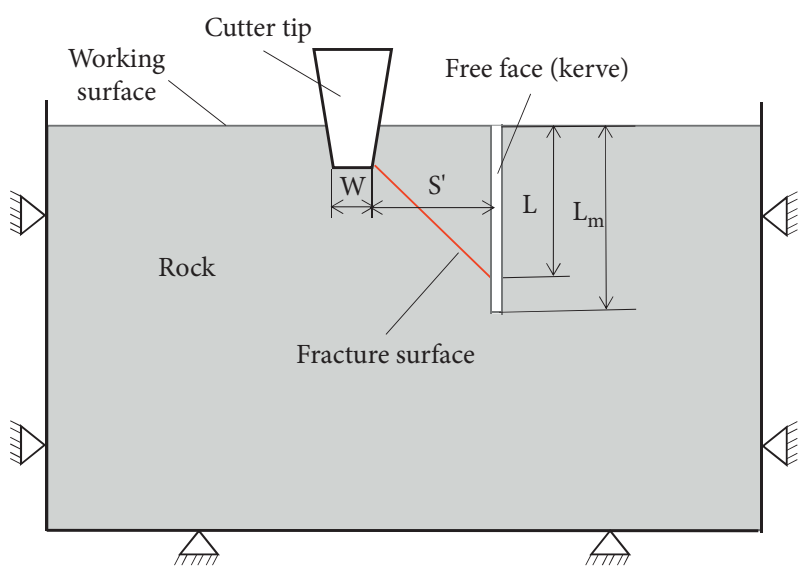

(b)

Figure 1: Schematic diagrams of two equivalent FM. (a) The completely free surface, (b) the deep curved free surface.

was large in the tensile stress region $[24,25]$. Li et al. conducted tension-shear tests on granite and found that the shear failure strength in the tension-shear region decreased rapidly as the tensile stress grew in the $\tau-\sigma$ stress space, and piecewise characteristics of strength curves are significant [26]. Huang and Zhu used sandstone to perform rock breaking tests, compared the test results with the calculated data from different rock strength criteria (Figure 2), and proposed a piecewise linear failure criterion as equation (1), which was proved to show a higher estimation accuracy for both the tensile and compressive states of rocks [22].

$$
\left\{\begin{array}{l}
\tau_{f}=3.77\left(\sigma_{n}-\sigma_{t}\right) \quad \sigma_{n} \leq 0, \\
\tau_{f}=\sigma_{n} \tan 57.46^{\circ}+5.50 \quad \sigma_{n} \geq 0 .
\end{array}\right.
$$

Based on the FM rock breaking mechanism analysis and the piecewise strength criterion for sandstone [22], we propose a piecewise linear strength criterion for hard rocks to simplify the calculations (Figure 3 ). In our criterion, the $\mathrm{M}-\mathrm{C}$ is adopted under compression-shear stress, and $\mathrm{H}-\mathrm{B}$ is replaced by linear curves under tension-shear stress (Equation (2). According to the strength criterion, the FM failure surface is under the tensile-shear stress state, including both tensile failure and shear failure, and tensile stress is the most influential form of stress on the failure surface. The rock strength is lower under the tension-shear stress state compared to the compression-shear stress state. Therefore, due to the synergistic effect on the free face, the rock breaking process is better described as a tension-shear fracture in FM instead of compression-shear fracture in CM, which produces a large volume of rock fracture with less rock breaking forces.

$$
\begin{cases}\tau_{n}=c+\tan \varphi_{t} \cdot \sigma_{n}, & \left(\sigma_{t} \leq \sigma_{n} \leq 0\right) \\ \tau_{n}=c+\tan \varphi_{b} \cdot \sigma_{n}, & \left(\sigma_{n}>0\right)\end{cases}
$$

where $\tau_{n}$ represents the shear stress on the failure surface; $\sigma_{n}$ is the effective normal stress on the failure surface, in which the compressive stress is positive and the tensile stress is negative; cis the inherent shear strength or rock cohesion $[17,23] ; \varphi_{t}$ is the approximate internal friction angle in the tension-shear region, which is defined as $\varphi_{t}=\arctan \left(c / \sigma_{t}\right)$, where $\sigma_{t}$ is the uniaxial tensile strength (UTS); and $\varphi_{b}$ is the angle of internal friction [23].

\section{Calculation Model for the Key Parameters in FM}

The cutting force analysis in the FM state is shown in Figure 4. The key parameters to be calculated include the crushing angle $\psi$, the maximum free space distance $S_{\max }^{\prime}$, and the cutting force.

3.1. Calculation of the Crushing Angle (Figure 5). In Figure 5, the plane $\square \mathrm{ABCD}$ is the rock fracture section under FM. With the friction taken into consideration and assuming that the forces acting on the blade are evenly distributed, the friction angle corresponding to the friction can be represented as $\beta$. The line $L_{\mathrm{AB}}$ represents the surface of the rock that contacts the side face of the cutter blade. The line $L_{\mathrm{AD}}$ represents the rock failure surface, on which both shear stress $\tau_{n}$ and tensile stress $\sigma_{n}$ are present and their resultant forces are shear force $T$ and normal tension $N$, respectively. The resultant force from the blade that acts on the fracture body is represented as $P_{2}$, and when $\tau_{n}$ and $\sigma_{n}$ satisfy equation (2), the rock fracture occurs. The calculation equations of the two stresses are deduced from the geometric characteristics of the broken body, and all the parameters mentioned above meet the following equations: 


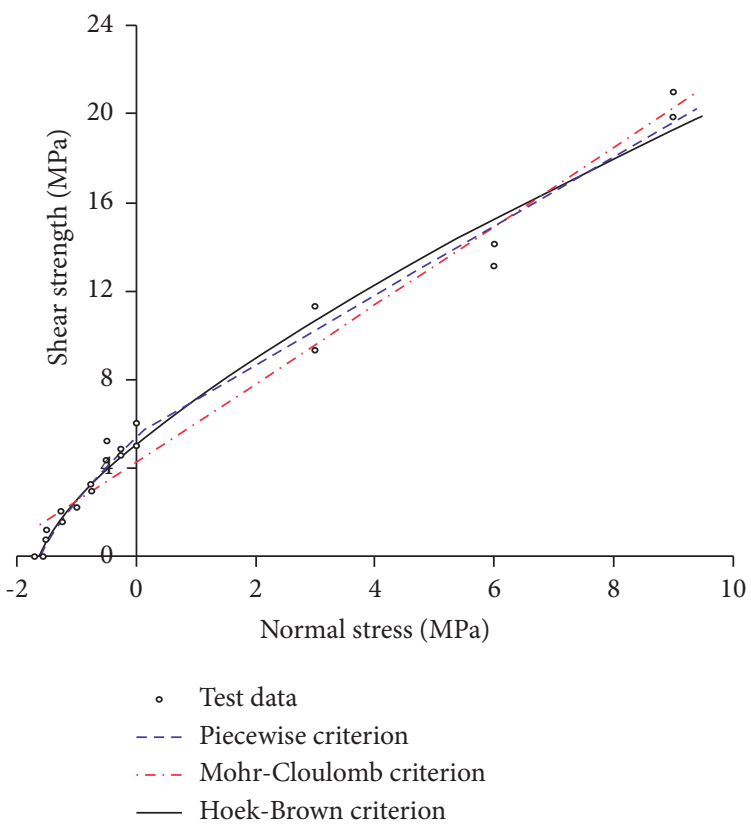

Figure 2: Shear strength versus normal tensile stress and fitting strength envelopes [22].

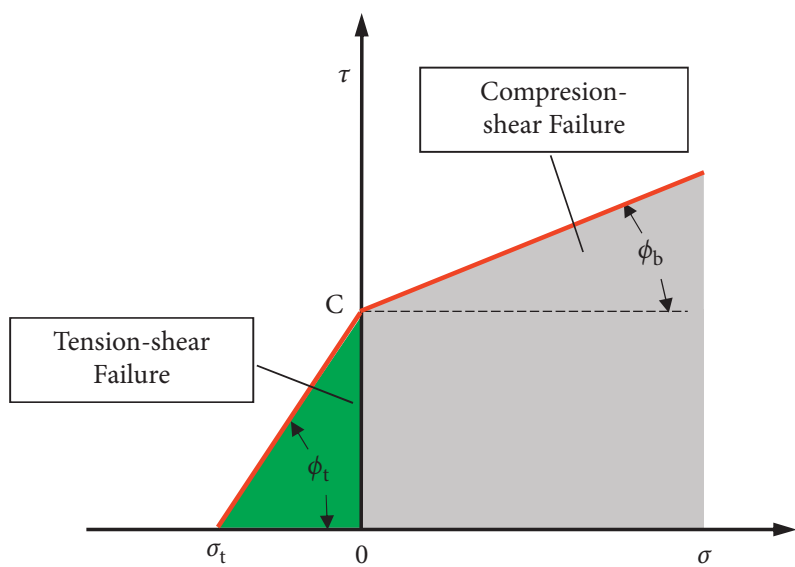

FIgURE 3: The schematic diagram of piecewise linear strength criterion.

$$
\begin{gathered}
\tau_{n}=\frac{T}{L_{\mathrm{AD}}}=\frac{P_{2}}{L_{\mathrm{AD}}} \sin (\theta+\beta+\psi), \\
\sigma_{n}=-\frac{N}{L_{\mathrm{AD}}}=-\frac{P_{2}}{L_{\mathrm{AD}}} \cos (\theta+\beta+\psi),
\end{gathered}
$$

where $L_{\mathrm{AD}}$ is the length of line $\mathrm{AD}, L_{\mathrm{AD}}=S^{\prime} / \sin \psi, \theta$ is the semi-cone angle of the blade, and $\psi$ is the rock crushing angle. Put equations (3) and (4) into equation (2), and we get:

$$
\tau_{n}-\sigma_{n} \cdot \tan \varphi_{t}=\frac{P_{2}}{S^{\prime} \cdot \cos \varphi_{t}} \sin \psi \cdot \sin \left(\theta+\beta+\psi+\varphi_{t}\right)=c
$$

Given a certain cutter structure and set of rock breaking parameters, the expression $\left(\tau-\sigma \mu_{\mathrm{t}}\right)$ is a continuous function of $\psi$, so a certain $\psi$ may exist where $\left(\tau-\sigma \mu_{\mathrm{t}}\right)$ is at its maximum and that is the situation where the rock is the most likely to fracture ( $\psi=$ crushing angle). Then, take the derivative of equation (5) with $\psi$ as the variable and setting the derivative to zero, we get

$$
\sin \left(\theta+\beta+2 \psi+\varphi_{t}\right)=0
$$

In equation (6), all angles are positive, and the physical meanings and value ranges of each angle parameter suggest that $\left(\theta+\beta+2 \psi+\varphi_{t}\right)<2 \pi, \quad$ so $\quad \theta+\beta+2 \psi+\varphi_{t}=\pi$. Therefore,

$$
\psi=\frac{\pi}{2}-\frac{\beta+\varphi_{t}+\theta}{2}
$$

According to equation (7), under FM, the value of the rock crushing angle is relatively stable, which is determined 


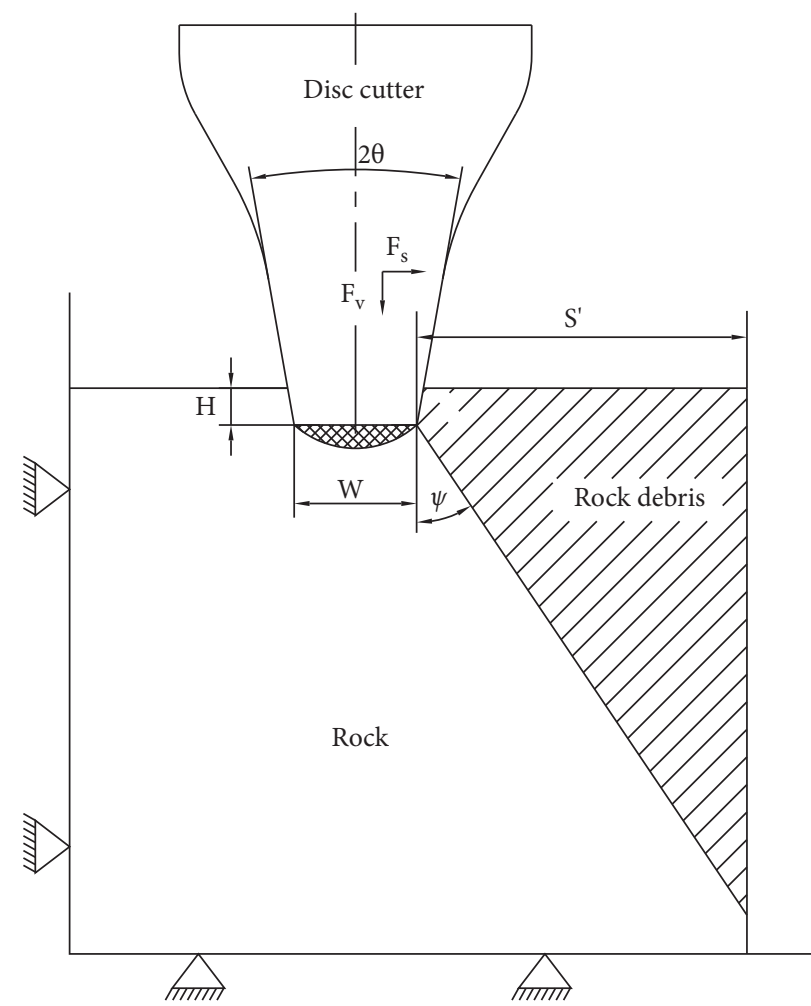

FIGURE 4: Analysis of cutting force for FM.

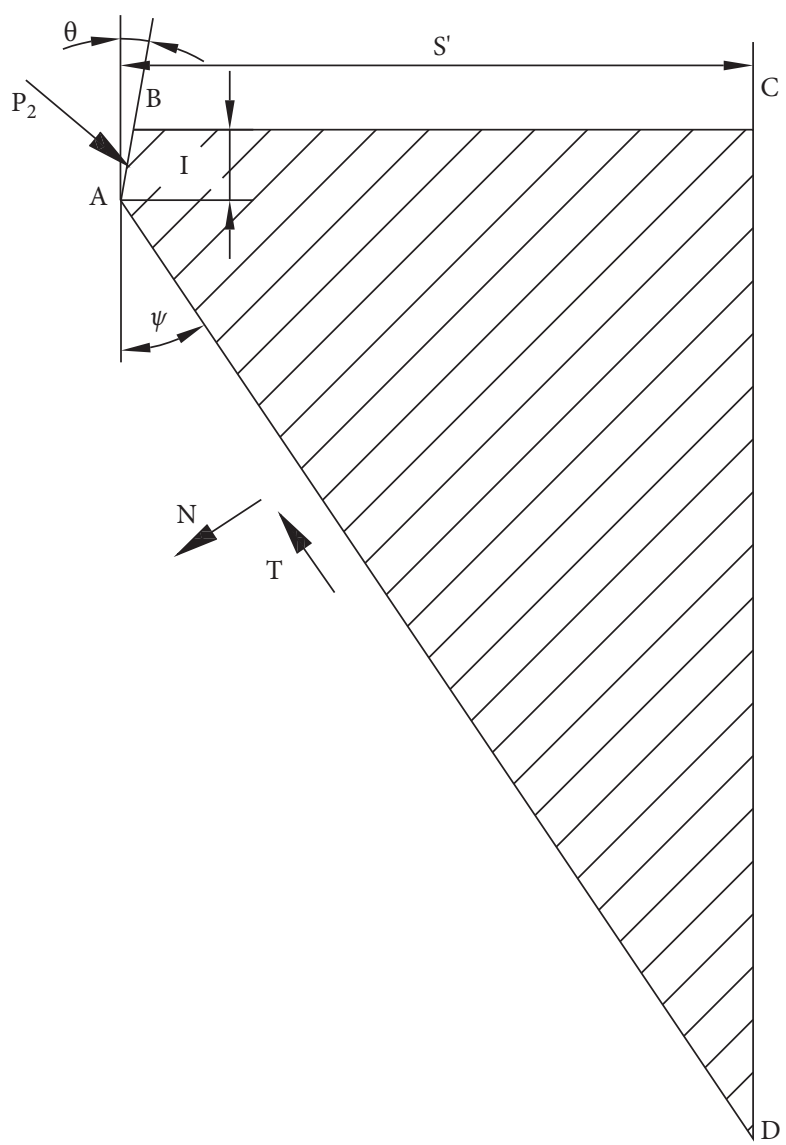

FiguRe 5: Force analysis diagram of the rock fracture body for disc cutter in FM. 
by the rock characteristic parameters $\left(\beta\right.$ and $\left.\varphi_{t}\right)$ and the cutter structure $(\theta)$.

3.2. The Calculation of the Maximum Free Space Distance $S_{\max }^{\prime}$. According to Figure 5, the lateral resultant force $P_{2}$ is the primary cause for rock fractures to happen on the free face side. $P_{2}$ increases as the cutter penetrates the rock, and the area of rock contacting the blade side face also rises, further boosting the power of $P_{2}$ until rock fracture occurs. After that, $P_{2}$ drops quickly. Therefore, the maximum of $P_{2}$ appears at the moment of rock breaking, and the crushing angle $\psi$ can be calculated by equation (7).

When cutter penetration is stable, no FM effects would occur when the free space distance $S^{\prime}$ exceeds the maximum free space distance $S_{\max }^{\prime}$. Therefore, we can consider $S_{\max }^{\prime}$ as the boundary between FM and CM, and a force equilibrium may occur between $P_{2}$ and $P_{2}^{\prime}$ at $S_{\max }^{\prime}$ (see Figure 6 and equation (11)).

3.2.1. The Calculation of $P_{2}$ under FM. Judging from Figure $5, L_{\mathrm{AB}}=H / \cos \theta$, and $q_{2}$ is the average stress acting on the rock. Starting from equation (5), we can obtain the following equations:

$$
\begin{aligned}
& P_{2}=\frac{c \cdot \cos \varphi_{t}}{\sin \psi \cdot \sin \left(\theta+\beta+\psi+\varphi_{t}\right)} \cdot S^{\prime} . \\
& q_{2}=\frac{P_{2}}{L_{\mathrm{AB}}}=\frac{\cos \theta \cdot c \cdot \cos \varphi_{t}}{\sin \psi \cdot \sin \left(\theta+\beta+\psi+\varphi_{t}\right)} \cdot \frac{S^{\prime}}{H} .
\end{aligned}
$$

Equations (8) and (9) show that when the cutter structure $(\theta)$, rock characteristics $\left(\varphi_{t}\right)$, and cutting conditions $\left(S^{\prime}\right.$ and $H$ ) are given, the lateral resulted force $P_{2}$ can be calculated. $q_{2}$ is proportional to $S^{\prime}$ and inversely proportional to the penetration $H$.

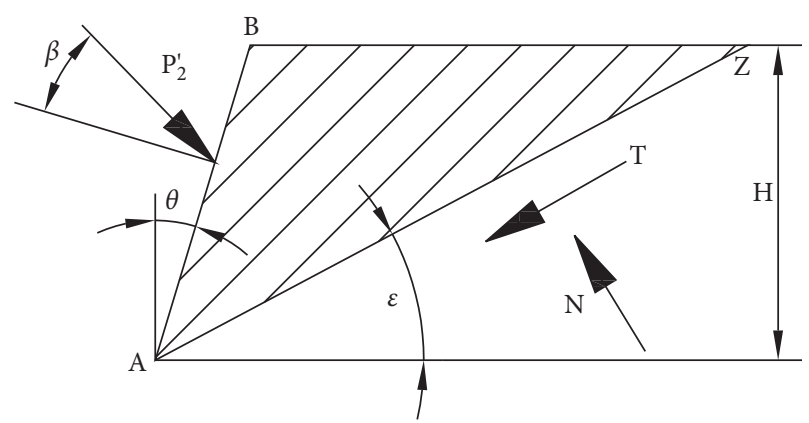

FIGURE 6: Stress analysis of rock fracture body under compressionshear stress state in $\mathrm{CM}$.

3.2.2. The Calculation of $P_{2}^{\prime}$ in $C M$. Tu analyzed the force equilibrium in the rock fracture body caused by a compression-shear failure under CM (Figure 6) and proposed the force calculation equations as equations (10) and (11) [27].

$$
\begin{aligned}
& q_{2}^{\prime}=\frac{c \cdot \cos \varphi_{b} \cdot \cos \theta}{\cos \left(\theta+\beta+\varepsilon+\varphi_{b}\right) \cdot \sin \varepsilon}, \\
& P_{2}^{\prime}=q_{2}^{\prime} * L_{A B}=\frac{H \cdot c \cdot \cos \varphi_{b}}{\cos \left(\theta+\beta+\varepsilon+\varphi_{b}\right) \cdot \sin \varepsilon},
\end{aligned}
$$

where $P_{2}^{\prime}$ is the resultant force acting on the $L_{\mathrm{AB}}$ of the rock body from the cutter blade and the average stress of $P_{2}^{\prime}$ is $q_{2}^{\prime}$ and $\varepsilon$ is the angle of compression-shear failure face. The semi-cone angle $\theta$ should satisfy $\left(\theta+\beta+\varepsilon+\varphi_{\mathrm{b}}\right)<\pi / 2$; otherwise, the compression-shear failure will not occur. At $S_{\max }^{\prime}$, the lateral force $P_{2}$ under FM is assumed to be balanced by $P_{2}^{\prime}$ in CM. So, equations (12) and (13) can be established from equations (8) and (11):

$$
\begin{aligned}
& \frac{c \cdot \cos \varphi_{t}}{\sin \psi \cdot \sin \left(\theta+\beta+\psi+\varphi_{t}\right)} \cdot S_{\max }^{\prime}=\delta_{1} \cdot \frac{H \cdot c \cdot \cos \varphi_{b}}{\cos \left(\theta+\beta+\varepsilon+\varphi_{b}\right) \cdot \sin \varepsilon}, \\
& S_{\max }^{\prime}=\kappa_{1} \cdot \delta_{1} \cdot H, \\
& \kappa_{1}=\frac{\cos \varphi_{b} \cdot \sin \psi \cdot \sin \left(\theta+\beta+\psi+\varphi_{t}\right)}{\cos \left(\theta+\beta+\varepsilon+\varphi_{b}\right) \cdot \sin \varepsilon \cdot \cos \varphi_{t}} .
\end{aligned}
$$

Here, $\kappa_{1}$ is a constant related to the rock material and rock breaking parameters and $\delta_{1}$ is a correction factor, which is 6 in this paper. Equation (13) shows that $S_{\max }^{\prime}$ is proportional to the penetration $\mathrm{H}$ when rock breaking conditions are given.

3.3. Calculation of Cutting Forces on the Cutter. The cutting forces on the disc cutter, including normal force $F_{V}$, rolling force $F_{R}$, and side force $F_{S}$, are fundamental to cutter head designing. Scholars have made intensive studies on them and proposed a variety of force models. At present, the most widely used model is the CSM model from the Colorado Institute of Mining, which is based on a large number of linear rock breaking tests (equations (15)-(17)) $[14,28,29]$.

CSM model is predominantly applicable in CM, and it ignores the calculation of side force [30]. A comparative test showed that the calculation results from the CSM model are smaller than the actual values [31]. Therefore, the final 
parameters used in practical engineering are often obtained by modifying the calculation results of the CSM model (e.g. multiply the results by a coefficient). In this paper, we attempt to modify the CSM model to make it applicable to FM.

A comparative experimental study between FM and CM [11] found that the variations of normal force and rolling force under FM are similar to those in CM, and the rolling force varies almost linearly. According to equation (17), under a certain penetration, the rolling force is determined by the normal force. Therefore, a proportional relationship can be assumed between the cutter forces in these two rock breaking modes, and the cutter forces under FM can be expressed as $F_{N-\mathrm{FM}}=\lambda \cdot F_{N}, \quad F_{R-\mathrm{FM}}=\lambda \cdot F_{R}$, where $\lambda=0.75$. In addition, since there are no adjacent cutters on the free face side under FM, the cutter spacing $S$ in the CSM model needs to be converted into $S^{\prime}+0.5 W$, when calculating the cutter stress under FM, where $W$ is the cutter blade width.

$$
\begin{aligned}
& P_{r}=C \sqrt[3]{\frac{S}{\alpha \sqrt{R W}} \sigma_{c}^{2} \sigma_{t}}, \\
& F_{N}=T \cdot R \cdot \alpha \cdot P_{r}, \\
& F_{R}=F_{N} \tan \left(\frac{\alpha}{2}\right) .
\end{aligned}
$$

In the equations above, $P_{r}$ is the base stress; $C$ is a constant of 2.12; $\sigma_{c}$ is the uniaxial compressive strength; and $\alpha$ is the angle of the contact arc.

For the calculation of side force, previous research is mainly based on the shear failure theory, which considers the side force being numerically equal to the force required to crush the rock between adjacent cutter grooves and a lateral component of the normal force $[27,30]$. Because the cutter and its mounting structure are not completely rigid, so in this paper, we consider the occurrence of slight deformation under side force. In this case, the magnitude of the side force can be reflected by its rock breaking effect under FM, and it can be expressed as the force required for rock breaking on the free face side. For the most widely used constant crosssection disc cutters (CCS), the horizontal projection of the contact area between the blade and the rock can be described approximately by a triangle $S_{\mathrm{ABE}}$, and the vertical projection of the contact area between the bottom of the blade and the rock can be described approximately by a trapezoidal area

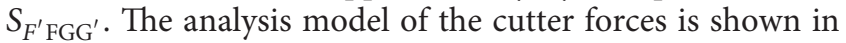
Figure 7 [27, 32], and the side force calculation model is proposed as

$$
\begin{aligned}
F_{2}=\frac{S_{\mathrm{ABE}}}{\cos \theta} \cdot q_{2} & =\frac{r \cdot \sin \alpha \cdot c \cdot \cos \varphi_{t}}{2 \sin \psi \cdot \sin \left(\theta+\beta+\psi+\varphi_{t}\right)} \cdot S^{\prime}, \\
F_{S} & =\delta_{2} \cdot F_{2} \cdot \cos (\theta+\beta),
\end{aligned}
$$

where $F_{2}$ is the resultant force acting on the contact area of the cutter near the free face and $\delta_{2}$ is the reduction coefficient, whose empirical value in this paper is 0.2 .

\section{Test and Analysis}

The FM tests were carried out on the LCM in Central South University, and the test platform is depicted in Figure 8. The rock was placed in the mounting frame, and the front and rear ends of the rock sample were pressed and fixed by steel plates and bolts. The left and right sides of the rock were free faces. The rock sample was gneiss with a uniaxial compressive strength of $\sigma_{c}=145.2 \mathrm{MPa}$ and a tensile strength of $\sigma_{t}=6.72 \mathrm{MPa}$. The inherent shear strength is

$$
c=\frac{\sigma_{c}}{2} \cdot \frac{1-\sin \varphi_{b}}{\cos \varphi_{b}}=38 \mathrm{MPa}
$$

The internal friction angle of gneiss under compressionshear stress was taken as an empirical value $\varphi_{\mathrm{b}}=35^{\circ}[31]$. According to equation (2), the friction angle under tensionshear stress is

$\varphi_{t}=\arctan \left(C / \sigma_{t}\right)=80^{\circ}$. The half-angle of the cutter blade was $\theta=10^{\circ}$, and the blade width $W$ was $20 \mathrm{~mm}$. Rock crushing angle $\varepsilon$ was relatively stable between $15^{\circ}$ and $30^{\circ}$, and $\varepsilon=15^{\circ}$ was taken in this paper [34]; The relationship between the friction angle and friction coefficient is $\eta=\tan \beta$, and the friction coefficient $\eta$ between the steel structure and rock is generally taken as 0.3 in TBM designs, so $\beta=16.7^{\circ}$ in this paper.

4.1. Model Verification of Crushing Angle. Put the actual test parameters into equation (7), and we can get the theoretical crushing angle $\psi$ :

$$
\psi=\frac{\pi}{2}-\frac{\beta+\varphi_{t}+\theta}{2}=36.65^{\circ}
$$

As the FM fracture surface is not a regular plane, the actual $\psi$ cannot be measured directly. Therefore, a conversion formula was proposed:

$$
\psi=57.3^{\circ} \cdot \operatorname{arccot}\left(\frac{h^{\prime}-H}{S^{\prime}}\right) .
$$

Here $h^{\prime}$ represents the maximum vertical height on the free face side of the fracture body, i.e. the length of the straight line $L_{\mathrm{CD}}$ in Figure 5. The location of maximum depth $h^{\prime}$ on the crushing surface and two points near its two sides were selected as the measuring positions, and the measured data were averaged to obtain the test value of $h^{\prime}$. Typical rock breaking states under FM are given in Figure 9, and the test data of $\psi$ are shown in Table 1.

From Table 1, we can tell that $\psi$ decreased with deeper $H$ but increased with larger $S^{\prime}$, and its maximum was smaller than what the model calculated. From such findings, the crack distribution and propagation laws under the cutter could be analyzed (Figure 10). Around the dense core below the cutter, cracks distributed radially on both sides of the cutter blade, and the crack propagation abilities varied in different directions. Specifically, the vertical cracks and oblique cracks under the cutter are most prone to propagation [33]. 


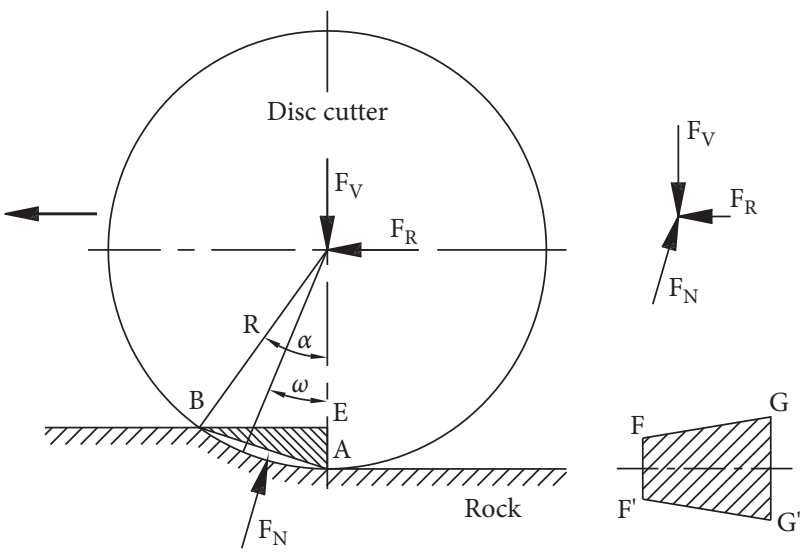

FIgURE 7: Analysis of cutting force for disc cutter.

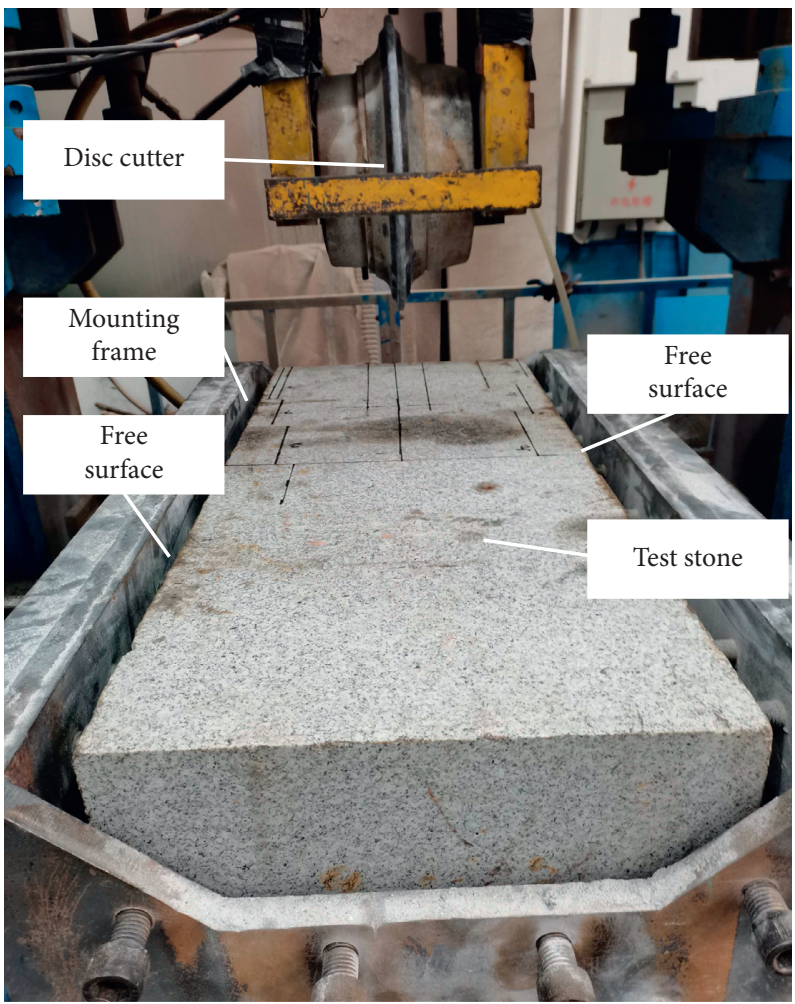

Figure 8: Test system.

Under FM conditions, cracks under the cutter propagate to the free face and form an inclined fracture surface with a certain angle [12]. Based on the analysis models in Figures 4 and 5, both the normal force and side force are considered necessary to create fracture surfaces with different inclination angles, and $\psi$ values also differ in the tension-shear fracture mode. When the rock breaking conditions are given, fracture surfaces with large $\psi$ values are more prone to break, so $\psi$ should increase with higher $S^{\prime}$ numbers toward its maximum near $S_{\max }^{\prime}$ (FM rock fracture cannot occur when $S^{\prime}>S_{\max }^{\prime}$ ). When $S^{\prime}$ is kept constant and $\mathrm{H}$ is deep enough to trigger $\mathrm{FM}$ rock breaking, a through crack will occur and an FM fracture would come as a result. Increasing $H$ further will expand the vertical and oblique cracks in the unbroken area under the cutter to create more crack fractures. The subsequent fracture surfaces (equivalent to smaller $\psi$ values) are generally more inclined than the first one. Moreover, since the actual FM fracture surface is not a regular plane, $h^{\prime}$ is discrete. In this paper, $h^{\prime}$ values applied to equation (22) were measured at the maximum $h^{\prime}$ positions, and consequently, the obtained $\psi$ values were smaller than the actual ones. By measuring $h^{\prime}$ at more locations and take the average, $\psi$ calculated by equation (22) would become larger and closer to the value obtained in the estimation model. 

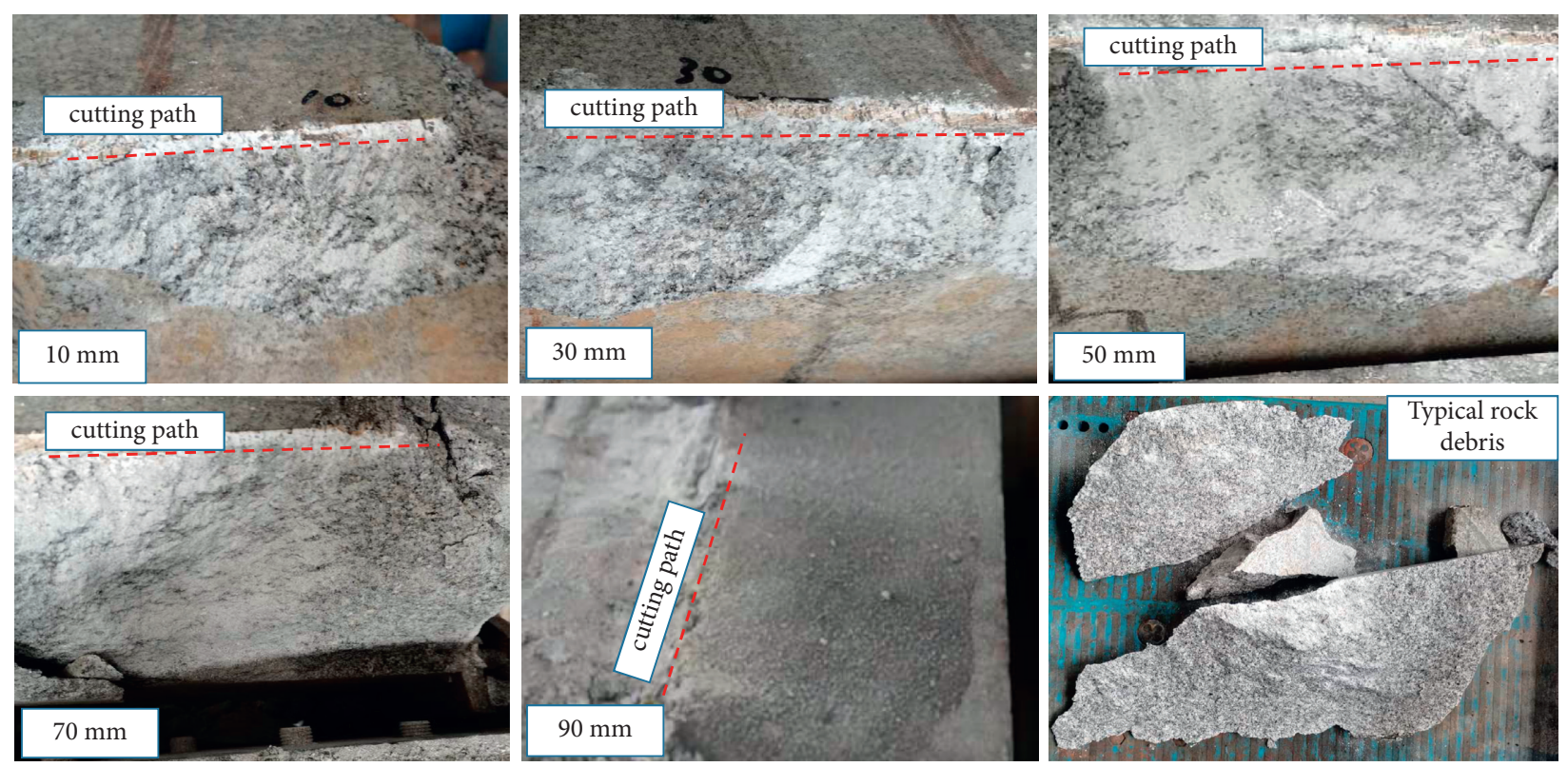

FIgUre 9: Typical state of fracture surface in different $S^{\prime}$, penetration $H=6 \mathrm{~mm}$.

TABLE 1: The $\psi$ test values and model values under different penetration depths.

\begin{tabular}{|c|c|c|c|c|c|}
\hline$S^{\prime}(\mathrm{mm})$ & 10 & 30 & 50 & 70 & 90 \\
\hline Test value $\psi, H=3 \mathrm{~mm}$ & $18.5^{\circ}$ & $25.3^{\circ}$ & - & - & - \\
\hline Test value $\psi, H=6 \mathrm{~mm}$ & $14.1^{\circ}$ & $25.5^{\circ}$ & $25.5^{\circ}$ & $27.1^{\circ}$ & - \\
\hline Test value $\psi, H=9 \mathrm{~mm}$ & $12.8^{\circ}$ & $17.2^{\circ}$ & $19.5^{\circ}$ & $24.2^{\circ}$ & $28.8^{\circ}$ \\
\hline Model value $\psi$ & & & $36.65^{\circ}$ & & \\
\hline
\end{tabular}

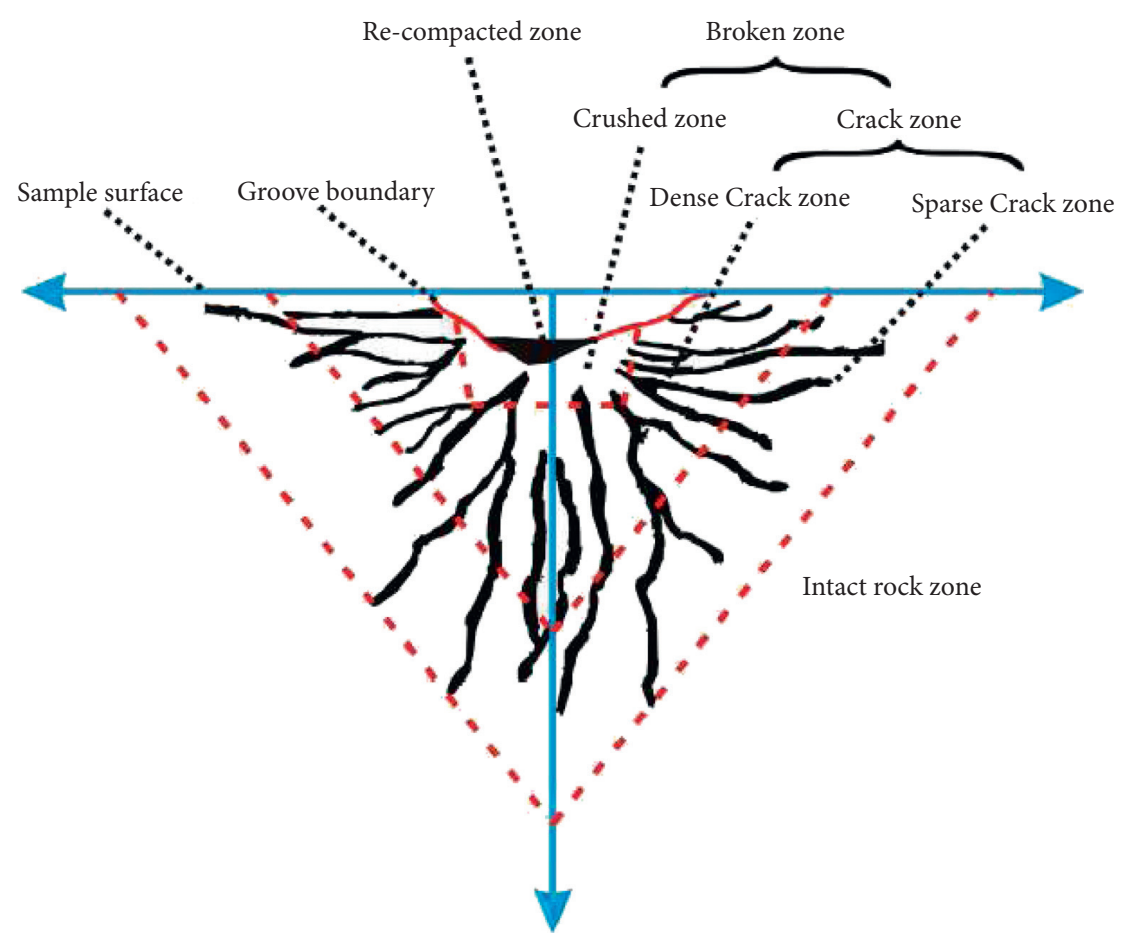

Figure 10: Cracking mode under one single cutter obtained from experiment [33]. 
In conclusion, the actual crushing angle $\psi$ is affected by $S^{\prime}$ and $\mathrm{H}$. The $\psi$ estimation model in this paper produces more accurate estimation results compared to the actual value under $S_{\max }^{\prime}$ in FM.

4.2. Model Verification of $S_{\max }^{\prime}$. $S_{\max }^{\prime}$ was calculated according to equations (13) and (14), and the tests were carried out with penetration depths of $3 \mathrm{~mm}, 6 \mathrm{~mm}$ and $9 \mathrm{~mm}$ and different $S^{\prime}$ values. In order to reduce the test workload, a close estimation between the maximum test free face distance, which is capable to produce FM rock breaking effects, and its next second largest free face distance, which cannot produce FM results, was used in this paper. The estimated values and model values of $S_{\max }^{\prime}$ are shown in Table 2 and Figure 11. Judging from the data, the prediction model had a relatively large error range under both small and large penetration depths, but it was relatively small (less than 10\%) when $\mathrm{H}$ was in the intermediate value $(H=6 \mathrm{~mm})$. Figure 11 also shows that when $H \leq 6 \mathrm{~mm}$, the model values matched with the test values linearly, and the error values were relatively constant; but when $H>6 \mathrm{~mm}$, the mutual errors started to extend. This situation can be explained because under constant rock breaking conditions (rock type, $S^{\prime}$, cutter), $S_{\max }^{\prime}$ and $H$ in the estimation model in this paper are linearly correlated, which are not exactly the real case, especially when $H$ is large. Therefore, this model could be improved for better estimation accuracy by adding a constant $\delta_{3}$ or modifying the constant $\delta_{1}$ as a variable related to $H$.

4.3. Verification of Cutting Force Model. A series of FM tests were carried out with $\mathrm{H}$ and $S^{\prime}$ as the variables. $H$ was chosen as $3 \mathrm{~mm}, 6 \mathrm{~mm}$, and $9 \mathrm{~mm}$, and $S^{\prime}$ was selected as $10 \mathrm{~mm}$, $30 \mathrm{~mm}, 50 \mathrm{~mm}, 70 \mathrm{~mm}$, and $90 \mathrm{~mm}$, respectively. $S_{\max }^{\prime}$ was calculated by equations (13) and (14), and the calculation data are shown in Table 2. Comparisons among the values obtained from the CSM model, the FM model (modified CSM model and side force model, equation (19)), and the test are shown in Figures 12-14

First, the values obtained from the FM test and the FM model were compared. When $S^{\prime} \leq S_{\max }^{\prime}$, the test values of normal force, rolling force, and side force revealed similar alteration trends, and they were all positively correlated with $S^{\prime}$. Besides, FM model values varied in a similar trend as the test values, and the error between them was relatively stable. When $S^{\prime}>S_{\max }^{\prime}$, the test values of normal force and rolling force increased rapidly before stabilizing, while the test values of side force decreased rapidly. This finding is because the side forces acting on both sides of the cutter in CM are roughly the same, but their directions are the opposite, leading to a small resultant force. When $S^{\prime}>S_{\max }^{\prime}$, all FM model values rose gently, in which the differences between the model and test values of normal force and rolling force increased first before dropping and that difference of side force continued to expand. This situation can be explained because the rock breaking mode has changed from FM to $\mathrm{CM}$, making the side force model no longer suitable for the analysis.
TABLe 2: Comparison of maximum free space distance $S_{\max }^{\prime}$.

\begin{tabular}{lccc}
\hline Penetration $(\mathrm{mm})$ & 3 & 6 & 9 \\
\hline The test value $(\mathrm{mm})$ & 30 & 75 & 100 \\
The model value $(\mathrm{mm})$ & 24.56 & 69.21 & 126.71 \\
Error $(\mathrm{mm})$ & -5.44 & -5.79 & 26.71 \\
Error range & $-18 \%$ & $-8 \%$ & $+27 \%$ \\
\hline
\end{tabular}

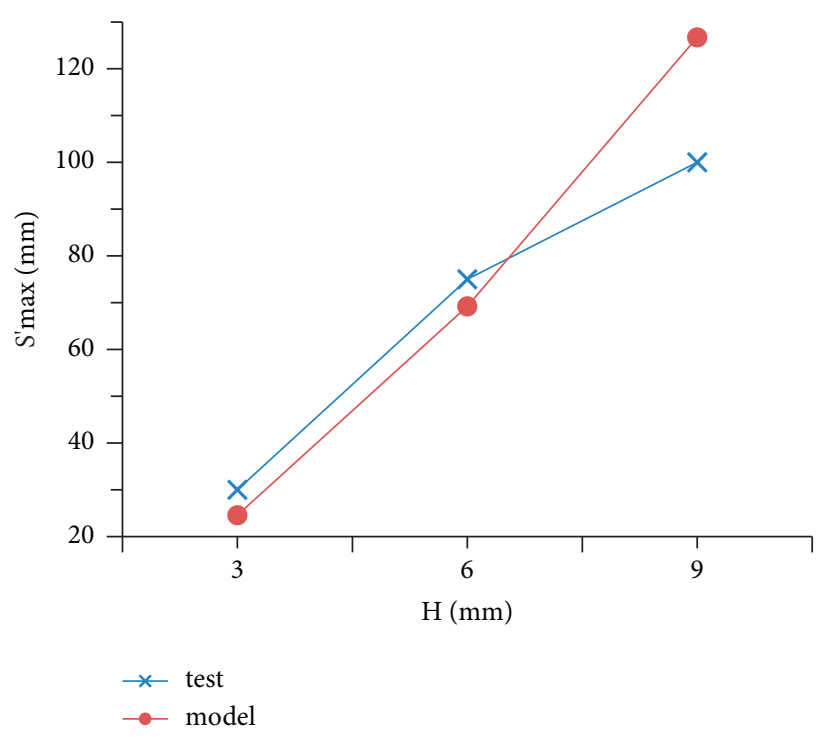

FIgURE 11: Comparison of $S_{\max }{ }^{\prime}$, test and model represent the test value and the model value in Table 2 , respectively.

In summary, there is a significant difference between FM and CM in terms of the values and change trends of cutting forces. When $S^{\prime} \leq S_{\max }^{\prime}$, the model values fit with the test ones well, suggesting good calculation accuracy on the cutting force in FM. When $S^{\prime}>S_{\max }^{\prime}$, only the normal force and the rolling force demonstrated similar trends between their model calculations and test results, but the absolute error of model calculations became large for all three cutting forces. Therefore, the side force model is not applicable when $S^{\prime}>S_{\max }^{\prime}$. It should be noted that the side force is the directional resultant force of the forces acting on both sides of the cutter. In FM, the side force constantly points to the side of the free face, which is also the case in coordinated rock breaking of adjacent tracks in some CM modes [35-37].

Moreover, under all $S^{\prime}$ conditions, the CSM model values (including normal force and rolling force) were greater than the test values in FM. Since the former is generally about $18 \%$ less than the latter in CM [30], it can be concluded that FM rock breaking can effectively reduce the normal force and rolling force in $\mathrm{CM}$ for $>30 \%$ under the same conditions. But when $S^{\prime}>S_{\max }^{\prime}$, the cutting force difference between the two rock breaking modes became smaller. Therefore, it can be deduced that with greater $S^{\prime}$, the rock breaking benefits of FM weaken gradually to complete disappearance. In a word, the rock breaking effect of FM should ensure $S^{\prime} \leq S_{\max }^{\prime}$ under the rock breaking conditions to make it effective. 


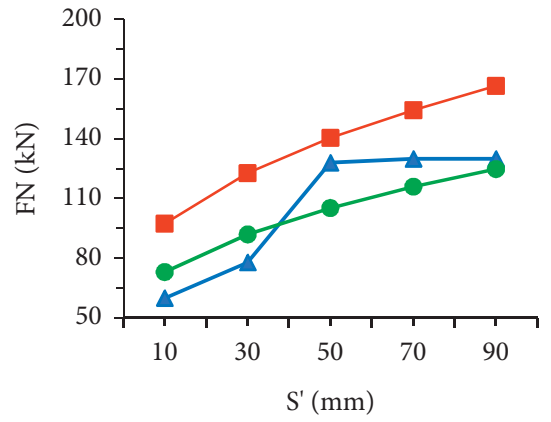

$\rightarrow$ FN-Test

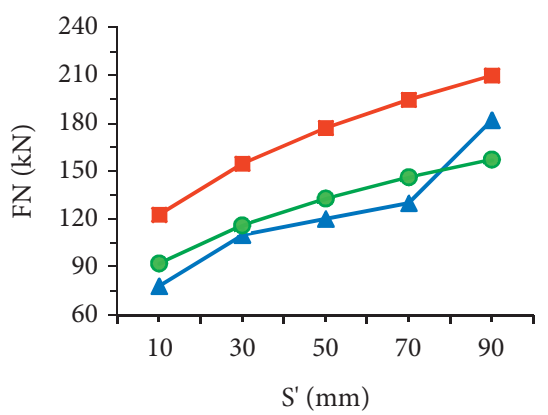

$\neg$ FN-Test

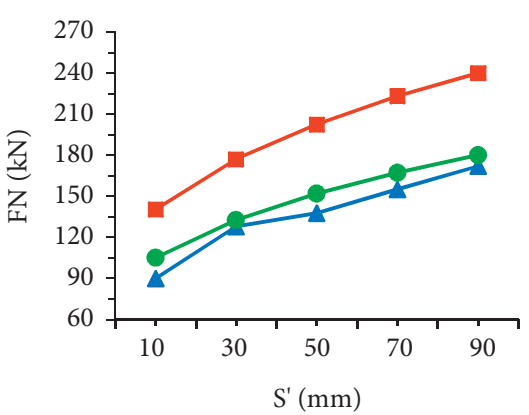

$\leftarrow$ FN-Test

(c)

Figure 12: Comparison of normal forces at different penetrations $H . F_{N-\text { Test }}$ is the test values of normal force under FM, $F_{N-F M}$ is the calculated values of normal force model under FM, and $F_{N-C S M}$ is the calculated values of normal force using CSM model. (a) Penetration $H=3 \mathrm{~mm}$. (b) Penetration $H=6 \mathrm{~mm}$. (c) Penetration $H=9 \mathrm{~mm}$.

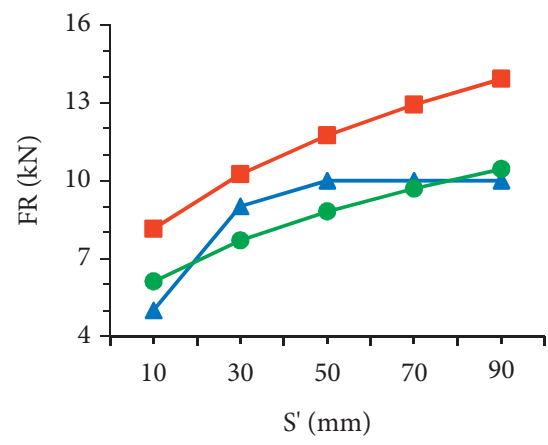

$₫$ FR-Test

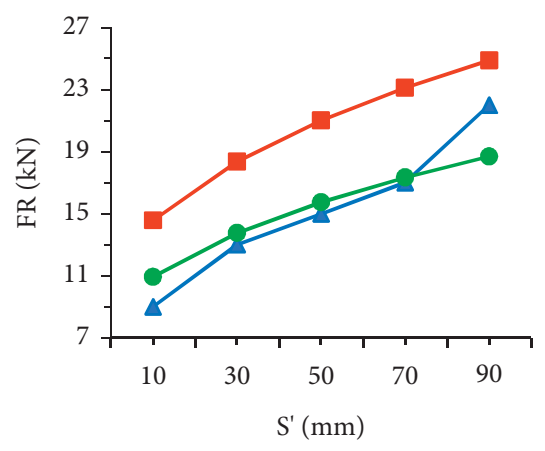

$\multimap$ FR-Test
$\multimap$ FR-CSM
$\rightarrow$ FR-FM

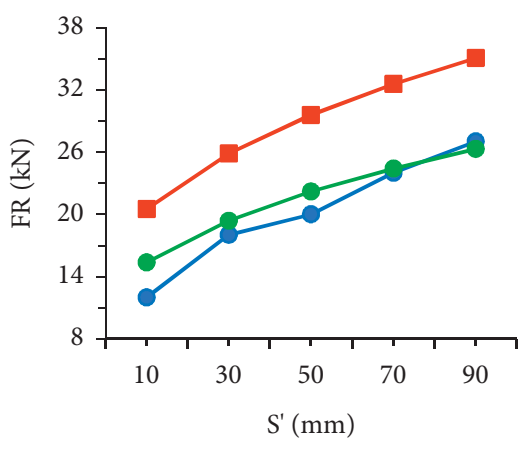

$\rightarrow$ FR-Test

(a)

(b)

(c)

Figure 13: Comparison of rolling forces at different penetrations $H . F_{R \text {-Test }}$ is the test values of rolling force under FM, $F_{R-F M}$ is the calculated values of rolling force model under FM, and $F_{R-C S M}$ is the calculated values of rolling force using CSM model. (a) Penetration $H=3 \mathrm{~mm}$. (b) Penetration $H=6 \mathrm{~mm}$. (c) Penetration $H=9 \mathrm{~mm}$.

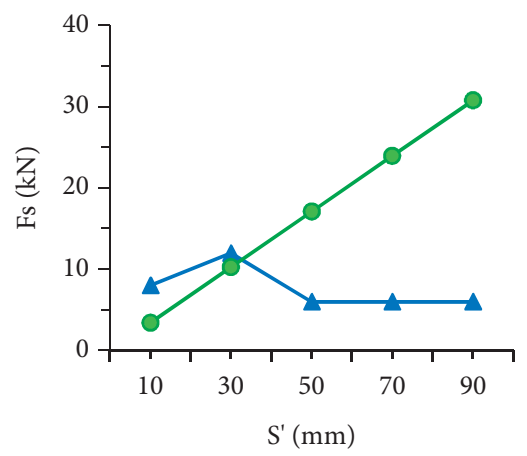

$\rightarrow$ FS-Test

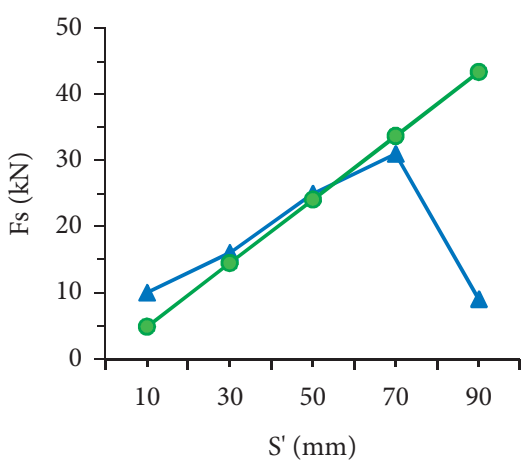

$\triangle$ FS-Test

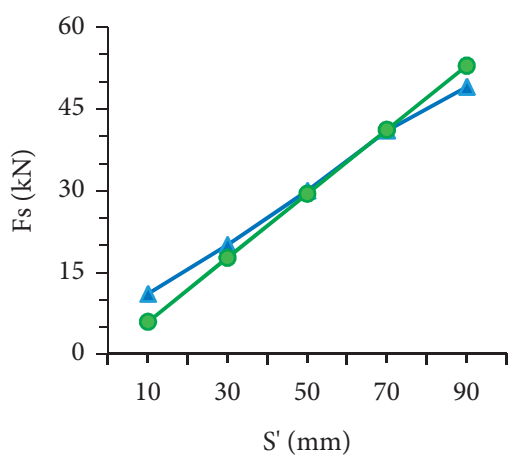

$\triangle$ FS-Test

(a)

(b)

(c)

Figure 14: Comparison of side forces at different penetrations $H . F_{S \text {-Test }}$ is the test values of side force under FM, $F_{S-F M}$ is the calculated values of side force model under FM. (a) Penetration $H=3 \mathrm{~mm}$. (b) Penetration $H=6 \mathrm{~mm}$. (c) Penetration $H=9 \mathrm{~mm}$. 


\section{Conclusions}

In this paper, the tension-shear failure mechanism of FM is proposed and discussed, and several estimation models for key parameters involved in FM, including the rock crushing angle, the maximum free space distance, and cutting forces (including modified CSM model and side force model), are established and analyzed for their calculation accuracy. The main conclusions are as follows:

(1) The tension-shear failure mechanism can be used to explain FM failure. In the $\tau-\sigma$ stress space, the Mohr-Coulomb criterion is more suitable to analyze the compression-shear region, and the Hoek-Brown criterion can be replaced by a linear failure criterion for the tension-shear region. In FM, the rock will crack under smaller tensile or shear strength compared to CM, which is the main reason that the force required for rock breaking reduces in FM.

(2) The maximum free face distance $S_{\max }^{\prime}$ can be used as the cut-off position for FM and CM rock breaking and $S_{\max }^{\prime}$ is linearly correlated with cutter penetration $H$. Meanwhile, it is affected by rock material, cutter structure, and rock breaking parameters.

(3) The rock crushing angle $\psi$ increases with the free space distance $S^{\prime}$ in FM and reaches its maximum at $S_{\max }^{\prime}$. The maximum $\psi$ can be estimated by $\psi=\pi / 2-\beta+\varphi_{t}+\theta / 2$.

(4) The modified CSM model (multiplied by a reduction coefficient $\lambda=0.75$ ) is feasible to apply to the cutting force estimation in FM, and it has good prediction accuracy when $S^{\prime} \leq S_{\max }$.

(5) The side force on cutters can be calculated by the lateral load required for rock breaking on the free face side under FM, but this method is not suitable when $S^{\prime}>S_{\max }^{\prime}$.

It should be noted that some rock material parameters quoted in the model calculations in this paper are from relevant manuals and empirical values. Due to the heterogeneity of rock materials, the estimation results may not apply to materials other than gneiss. In addition, the spatial structures and fracture surface shapes of rock fracture bodies under FM do not fully meet the assumptions of the estimation models in this paper. In particular, the constants (such as $\delta_{1}, \delta_{2}$, and $\lambda$ ) in the models were determined based on a small number of tests and experience, and their significance, scope of application, and calculation methods have not been studied in depth. Therefore, the models proposed in this paper still need further studies for wide applications, and they can only be used as a preliminary reference for the calculation of FM rock breaking as of today.

\section{Data Availability}

All data, models, and code generated or used during the study are included within the submitted article.

\section{Conflicts of Interest}

The author declares that there are no conflicts of interest.

\section{Acknowledgments}

This research was supported by Major Science and Technology Project of Hunan Province, China (ID 2019GK1011), National Key R\&D Program (2018YFC0808705) and China Railway Construction Corporation Limited (CRCC) Major Science and Technology Project "Kilometers shaft boring machine (2019-A03)." All the projects are undertaken by China Railway Construction Heavy Industry Corporation Limited (CRCHI). The author would like to thank Central South University for providing tests site and equipment support for thesis research.

\section{References}

[1] N. Bilgin, H. Copur, and C. Balci, "Effect of replacing disc cutters with chisel tools on performance of a TBM in difficult ground conditions," Tunn. Undergr.SpaceTechnolgy, vol. 27, p. 4151, 2012.

[2] L. Wang, Y. Kang, Z. Cai et al., "The energy method to predict disc cutter wear extent for hard rock TBMs," Tunnelling and Underground Space Technology, vol. 28, pp. 183-191, 2012.

[3] L. Wang, Y. Kang, X. Zhao, and Q. Zhang, "Disc cutter wear prediction for a hard rock TBM cutterhead based on energy analysis," Tunnelling and Underground Space Technology, vol. 50, pp. 324-333, 2015.

[4] Q. Geng, A. Bruland, F. J. Macias et al., "Analysis on the relationship between layout and consumption of face cutters on hard rock tunnel boring machines (TBMs)," Rock Mechanics and Rock Engineering, vol. 51, no. 1, pp. 279-297, 2018.

[5] A. Benato and P. Oreste, "Prediction of penetration per revolution in TBM tunneling as a function of intact rock and rock mass characteristics," International Journal of Rock Mechanics and Mining Sciences, vol. 74, pp. 119-127, 2015.

[6] R. Ciccu and B. Grosso, "Improvement of disc cutter performance by water jet assistance," Rock Mechanics and Rock Engineering, vol. 47, no. 2, pp. 733-744, 2014.

[7] F. Hassani, P. M. Nekoovaght, and N. Gharib, "The influence of microwave irradiation on rocks for microwave-assisted underground excavation," Journal of Rock Mechanics and Geotechnical Engineering, vol. 8, no. 1, pp. 1-15, 2016.

[8] T. Qing, Y. I. NianEn, S. YaoMing et al., "Study on the shockbreaking of shield machine cutter in transfer process," Southern Metals, vol. 5, pp. 5-9, 2016.

[9] G. Qi, W. Zhengying, H. Fei, and M. Hao, "Comparison of the mechanical performance between two-stage and flat-face cutter head for the rock tunnel boring machine (TBM)," Journal of Mechanical Science and Technology, vol. 29, no. 5, pp. 2047-2058, 2015.

[10] G. Qi, W. Zhengying, and M. Hao, "Numerical and experimental method to determine the boring diameters of a twostage TBM cutterhead to prevent rock burst," Journal of Mechanical Science and Technology, vol. 28, no. 11, pp. 4613-4620, 2014.

[11] Z. Xuhui, X. Yimin, T. Qing, and W. Dun, "Comparison study on the rock cutting characteristics of disc cutter under free- 
face-assisted and conventional cutting methods," KSCE Journal of Civil Engineering, vol. 22, 2018.

[12] X. h. Zhang, Y. m. Xia, G. y. Zeng, Q. Tan, and B. Guo, "Numerical and experimental investigation of rock breaking method under free surface by TBM disc cutter," Journal of Central South University, vol. 25, no. 9, pp. 2107-2118, 2018.

[13] B. Paul and D. L. Sikarskie, "A preliminary theroy of static penetration by a Rigid wedge into A brittle meterial," Transactions SME/AIME, vol. 232, pp. 372-382, 1965.

[14] J. Rostami, "Development of a force estimation model for rock fragmentation with disc cutters through theoretical modeling and physical measurement of crushed zone pressure," $\mathrm{PhD}$ thesis, Colorado School of Mines, Colorado, US, 1997.

[15] Q. Tang, N. E. Yi, Y. M. Xia, Y. Zhu, X. H. Zhang, and L. K. Ling, "Study of calculation equation of TBM disc cutter optimal spacing," Rock and Soil Mechanics, vol. 3, pp. 883$892,2016$.

[16] W. Dong, W. C. Liu, D. Wang, X.-D. Li, and X.-H. Xu, "Research on the tension-shear deformation and failure Criterion of rock under complex stress," Journal of Sichuan University (Engineering Science Edition), vol. 44, no. 2, pp. 31-35, 2012.

[17] E. Z. Lajtai, "Shear strength of weakness planes in rock," International Journal of Rock Mechanics and Mining Science \& Geomechanics Abstracts, vol. 6, no. 5, pp. 499-515, 1969.

[18] D. Huang and T.-T. Zhu, "Experimental and numerical study on the strength and hybrid fracture of sandstone under tension-shear stress," Engineering Fracture Mechanics, vol. 200, pp. 387-400, 2018.

[19] S. D. Li, X. Li, J. Y. Guo, J. He, and Y. Liu, "Research of rock failure testing under combined shear and tension," Journal of Engineering Geology, vol. 22, no. 4, pp. 1004-9665, 2014.

[20] D. F. Xia and H. Da, "Direct shear tests of sandstone under constant normal tensile stress condition using a simple auxiliary device," Rock Mechanics and Rock Engineering, vol. 50, no. 6, pp. 1425-1438, 2017.

[21] J. Chen, H. Zhou, Z. Zeng, and J. Lu, "Ma-cro-and microstructural characteristics of the tension-shear and compression-shear fracture of granite," Rock Mechanics and Rock Engineering, vol. 53, no. 1, Article ID 01896-4, 2019.

[22] D. Huang and T. Zhu, "Experimental study on the shear mechanical behavior of sandstone under normal tensile stress using a new double-shear testing device," Rock Mechanics and Rock Engineering, vol. 52, Article ID 01762-3, 2019.

[23] J. F. Labuz and A. Zang, "Mohr-coulomb mc failure criterion," Rock Mechanics and Rock Engineering, vol. 45, no. 6, pp. 975-979, 2012.

[24] E. Hoek, "Estimating Mohr-Coulomb friction and cohesion values from the Hoek-Brown failure criterion," International Journal of Rock Mechanics and Mining Science \& Geomechanics Abstracts, vol. 27, no. 3, pp. 227-229, 1990.

[25] E. Hoek and P. Marinos, "A brief history of the development of the Hoek-Brown failure criterion," Soils and Rocks, vol. 2, 2007.

[26] S. Li, L. Liu, X. Li, J. Guo, J. He, and Y. Liu, "Combined tension-shear experimental study of rock failure," in 2018 Proceedings of the GeoShanghai 2018 International Conference: Rock Mechanics and Rock Engineering, pp. 275-283, Cambridge University Press, Cambridge, England, 10 December 2009.

[27] C. F. Tu, "Study on the prediction model of vertical force and lateral force of shield machine disc cutter," Central South University, Changsha, China, Master Tesis, 2009.
[28] J. Rostami, "Study of pressure distribution within the crushed zone in the contact area between rock and disc cutters," International Journal of Rock Mechanics and Mining Sciences, vol. 57, pp. 172-186, 2013.

[29] L. Ozdemir, R. Miller, and F. D. Wang, "Mechanical tunnel boring prediction and machine design," Colorado School of Mines Annual Report, NASA STI/Recon Technical Report N, 1979.

[30] X. Jiang, "Study of the disc cutter performance forecasting model based on Courlomb-Mohr criterion," Journal of Mechanical Engineering, vol. 52, no. 20, p. 126, 2016.

[31] Geological Engineering Handbook Editorial board, Geological Engineering Handbook, Vol. 4, China Architecture \& Building Press, , Beijing, China, 2018.

[32] J. Rostami and L. Ozdemir, "New model for performance production of hard rock TBMs," in Proceedings of the - Rapid Excavation and Tunneling Conference, pp. 793-809, Springer, Boston, Massachusetts, US, 13 June 1993.

[33] X. B. Zhao, X. H. Yao, Q. M. Gong, H. S. Ma, and X. Z. Li, "Comparison study on rock crack pattern under a single normal and inclined disc cutter by linear cutting experiments," Tunnelling and Underground Space Technology, vol. 50, no. AUG, pp. 479-489, 2015.

[34] X. H. Xu and J. Yu, Rock Disintegration Mech-Anics, p. 11, China Coal Industry Publishing House, Beijing, China, 1984.

[35] X. X. Nan, Z. Ping, and Q. M. Gong, "The modelling of rock breakage process by TBM rolling cutters using 3D FEM-SPH coupled method," Tunnelling and Underground Space Technology, vol. 61, pp. 90-103, 2017.

[36] X. P. Zhou and S. F. Zhai, "Estimation of the cutterhead torque for earth pressure balance TBM under mixed-face conditions," Tunnelling and Underground Space Technology, vol. 74, pp. 217-229, 2018.

[37] H. Yang, H. Wang, and X. Zhou, "Analysis on the rock-cutter interaction mechanism during the TBM tunneling process," Rock Mechanics and Rock Engineering, vol. 49, no. 3, pp. 1073-1090, 2016. 